\title{
Småtræk fra Isted-slaget
}

\author{
Af Sigvard Skov.
}

I 1887 stiftedes museerne i Åbenrå og Haderslev, i 1889 påbegyndtes udgivelsen af Sønderjyske Årbøger, og i 1890 oprettedes Museet på Koldinghus. Den historiske interesse krævede nye virkeformer baseret på samvirke af flere ligesindede. At de nævnte ârstal betegner et nybrud og ikke en tilfældighed, ses. f. eks. af, at Koldinghus-museet har haft en forgænger, som ikke rigtig ville blive til noget, en oldsagssamling, som var inspireret fra Sønderjylland og delvis grundet på sønderjyske fund, nemlig den samling, som den i Angel fødte købmand Thomas Petersen (1831-94) i 1877 skænkede Kolding by. ${ }^{1}$

Da den lille oldsagssamling $\mathrm{i} 1890$ indgik som et led $\mathrm{i}$ det nystiftede Koldinghus-museums samlinger, anerkendte Thomas Petersen på den smukkeste måde det skete ved at tegne sig for et større årligt bidrag og ved at testamentere det Jurian Ovens store allegoriske maleri af Christiern I's apoteose, ${ }^{2}$ som stadig er perlen i museets billedsamling, og et værk af vægt i denne sønderjysk-frisiske malers europæisk berømte produktion. Fra grænsebyen Kolding var opmærksomheden sydvendt, og det gjaldt, som det ses, også museet på slottet. Intet tyder på, at museet i Haderslev følte sig generet af Koldinghus-museets indsamlinger syd for Kongeåen, for en pæn lille kollektion, f. eks. af kobbertøj, er ligefrem købt fra Haderslev Museum, der dengang som nu mest interesserede sig for de egentlige oldsager. Mere betænkeligt var det vel, at også haderslevske laugsklenodier gik mod nord. Men fra 1898 fandt Koldinghus det felt, hvor det kunne dyrke sine sønderjyske interesser $i$ en større sammenhæng og uden at gå naboernes interesser for nær, nemlig ved at give den påbegyndte samling af krigsminder, som oberst Vaupells testa- 
mentariske gave af konkrete personlige erindringer og relikvier yderligere stimulerede, en placering som et af museets væsentligste samleområder, endnu før man i Sønderborg var begyndt at lanke på den slags. Fra denne samling skal i det følgende fremdrages et par smâtræk om Isted-slaget, som vel ikke bringer noget epokegorende nyt om detles faktiske forlab, men som bringer et par $i$ al deres ubetydelighed karakteristiske detailler.

Den 24. juli 1850 stod den danske og den slesvig-holstenske hær ikke langt fra hinanden i landet mellem Flensborg og Slesvig. 1 begge hovedkvarterer ventede man, at den folgende dag maitte bringe afgørelsen og det store sammenstød. For at være sikker på initiativet havde den danske overgeneral Krogh bestemt sig for at være tidligt på farde. Kl. 3 om morgenen steg han til hest, og kl. 4 begyndte slaget. Langvarig og hård blev kampen og dens enkelte faser tildels meget dramatiske. Straks efter fremrykningen mod de slesvig-holstenske forposter sendte oberst von der Tann følgende melding til kommandøren for 1 . jægerkorps: "Die Meldung richtig erhalten. Der Feind hat unsere Vorposten angegriffen. Dieselben wurden etwas über Helligbeck zurïckgenommen. Das Gefecht ist vorläufig beendet".3

Denne melding fra den slesvig-holstenske hærs stabschef nåede imidlertid aldrig frem, idet ordonnansen blev taget til fange, da den danske hærs 5 . brigade under oberst $\mathrm{J}$. Ph. Rader indledte slaget $i$ et forsøg på at omgå slesvig-holstenernes venstre fløj. Til Ræder indgik lidt senere på morgenen to meldinger. Den første var skrevet $\mathrm{kl}$. 6,10 af oberstløjtnant J. Bülow, der var stabschef ved 2. division, som kommanderedes af general Schleppegrell, og som foruden Ræders brigade omfattede 1. brigade under oberst Krabbe og 2. brigade under oberst Baggesen. Bülows skrivelse, ${ }^{4}$ der er stilet både til oberst Ræder og general Krogh, lyder: Ankommen til Store Solt begyndte Engagementet. Fjenden trænges mod Isted af Avantgarden: 12. Bataillon og Batteriet Baggesen. Engagementet begyndte i vor venstre Flanke og trænges noget. Understøttelsen hen imod Store Solt og derfra ad Fahrenstedt anses nødvendigt". I virkeligheden var situationen betydelig mere faretruende, for umiddelbart før var Læssøe faldet, da han førte den nævnte 12. bataillon i et angreb på den af fjenden besatte Grydeskov, og lidt senere faldt Schleppegrell, 


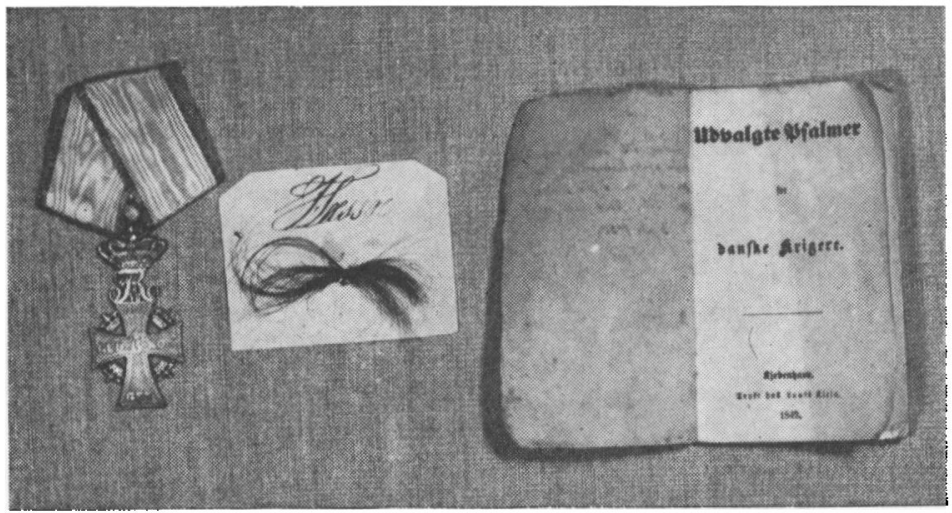

Laessøe-relikvier på Koldinghus.

da han $i$ spidsen for et rytteriangreb ville hindre fjenden $i$ at bemægtige sig et par af vore kanoner. Stabschefen, oberst Bülow, blev samtidig såret og taget til fange.

Uden at være fysisk helt $i$ orden havde general de Meza klaret hele felttoget i 1849 og endog vundet sig laurbær af første rang ved sin uforfærdede indsats i Fredericia-slaget, og havde han tidligere lidt bitre skuffelser, så smilede nu lykken til ham ${ }^{5}$ i form af hurtigt avancement fra major til oberstløjtnant, oberst og generalmajor i løbet af et års tid. Samtidig var en alvorlig sygdom i anmarch, og i marts 1850 blev han opereret, hvad dengang var en væsentlig vanskeligere affære end $i$ senere tider. Sygdommen hindrede de Meza $i$ at modtage valget som hærens øverstkommanderende ved felttogets begyndelse i 1850. Forst den 19. juli kunne han begive sig til hæren, altså netop tidsnok til at komme med i Isted-slaget. Krigsministeren havde tænkt sig, at de Meza skulle adjungeres general Moltkes division, hvad der kunne udlægges som en desavouering af Moltke, hvorfor de Meza i stedet sørgede for at være til disposition for den øverstkommanderende, general Krogh. I forvirringen efter Schleppegrells fald blev der god brug for de Meza. Herom vidner den lille seddel, ${ }^{6}$ som han straks efter sendte til oberst Ræder: „Jeg har modtaget Commandoen over 2. Division (efter at General Schleppegrell faldt) - men finder faa Fragmenter af den. - Krabbe usynlig -- 
Oberst Baggesen skilt ved sin Brigade. Jeg onsker at forene Deres Styrke med 3 Batailloner her staar af Oberst Thestrups Brigade (Ordonnansen vil vise Dem Stedet) - og har imidlertid sendt Bud til General Krogh om at rykke frem med 1. Division og siden Reserven for dog endelig een Gang at forcere Passet ved Idsted". De fả linier viser en general med et par ordonnanser i sit følge tage kommandoen over spredte og forsprængte troppestyrker, »få fragmenter « uden førere og en oberst uden brigade, for derefter at beslutte sig for det for slagets forløb afgørende gennembrud. Af de nævnte anførere kæmpede den ved denne lejlighed usynlige Oluf Krabbe dygtigt ved Vedelspang og hindrede derved fjenden $i$ at falde den danske hær i ryggen. Oberst August Baggesen (1795-1865), en søn af digteren, førte 2 . brigade, men var ikke fulgt med hovedparten af sin styrke, nemlig de tre batailloner, der var sendt mod Grydeskov. Den sabel, han forte i slaget, findes nu på Koldinghus. Dagen før havde de Meza skrevet $i$ sin dagbog, at han var $i$ "afkræftet tilstand". ${ }^{7}$ Formentlig har han befundet sig bedre på slagdagen, da han holdt sig $\mathrm{i}$ sadelen $i$ mere end 17 timer. Det lykkedes de Meza at få hold på de spredte styrker, nogen tid efter havde han 5000 mand kampklar, og ligeledes at få overkommandoen, hvor stabschefen, oberst Faaborg, var ved at forberede en tilbagetrækning, til at acceptere fremstødet. Det kronedes med held. Den danske hær gik frem til Danevirke, og slesvig-holstenerne trak sig tilbage til Ejderen.

General de Mezas indsats i Isted-slaget er blevet forskelligt bedømt. Den noget krakilske oberst Jacob Th. Ræder, en broder til den førnævnte brigadekommandør, erklærer „Jeg har Intet hørt til Generalens store Meriter"; 8 mens K. G. Rockstroh i sin biografi af generalen betoner, at de Mezas forholdsregler var "hetimelige og hensigtsmæssige". 9 Den her fremdragne lille seddel synes afgjort at veje til generalens fordel.

Efter Isted-slaget fejredes sejren ved et gallataffel. I dessertanretningens kransekage var anbragt en lille spilledåse, som med spinkle klange lod de kendte toner af „Dengang jeg drog afsted - " lyde. Dåsen, ${ }^{10}$ som vistnok er fransk, er siden kommet til Koldinghus. På låget bærer den en fremstilling af Napolcons bolig på St. Helena, og det er ingenlunde helt urimeligt, at Napo- 


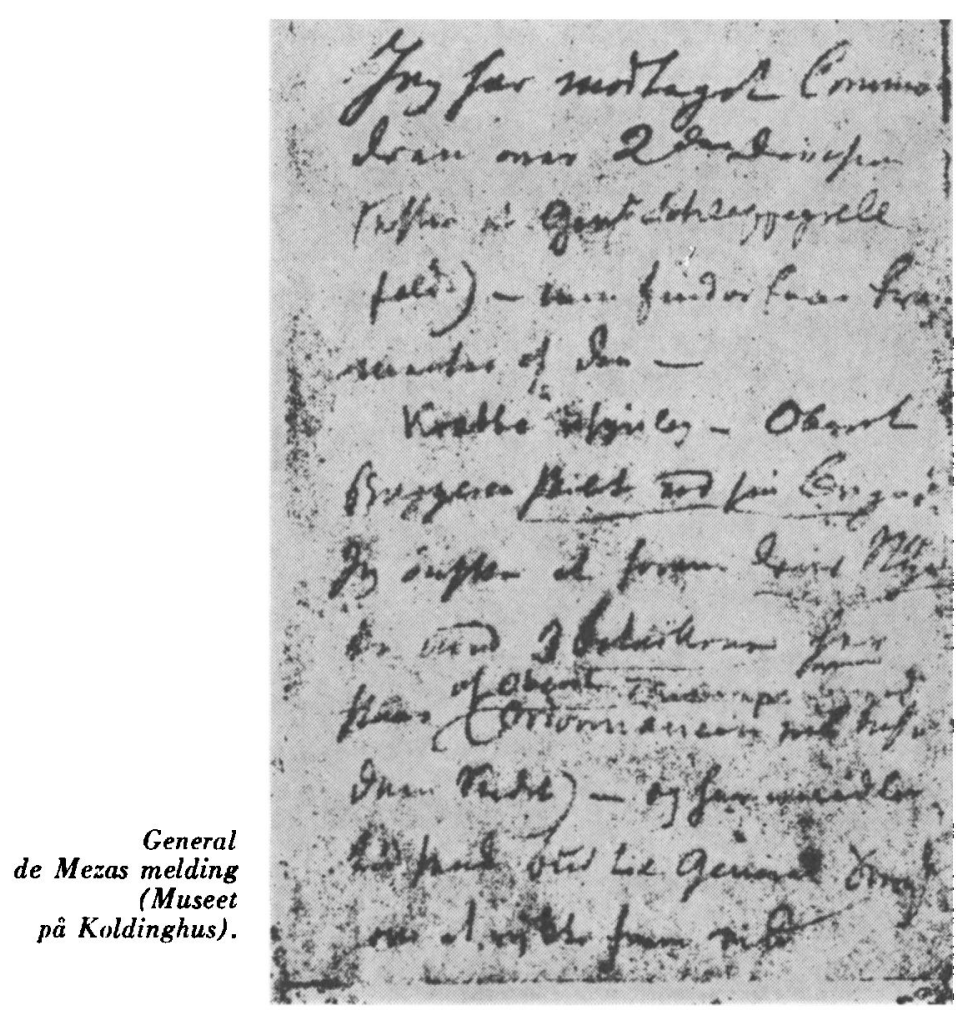

leon sâledes også kom med ved Isted. Treårskrigens danske officerer havde lært meget af Napoleons taktik. I denne forbindelse vil det være nærliggende at citere oberst J. Ph. Ræders angrebsordre ved slagets begyndelse: „Paa givet Signal styrter 1 . Træfning frem, kaster med Bajonetten alt over Ende, besæetter Нøjderne". Med rette har Rockstroh betegnet denne passus som ganske napoleonsk. C. J. de Meza deltog ikke i taflet. Sligt havde han ikke helbred til.

Efter besættelsen af Danevirke gik den danske hær ikke langere mod syd, og der forestod mange måneders vagt- og forposttjeneste kun afbrudt af mindre fægtninger. Både general Krogh og de Meza var lidet lydhore overfor krigsministeriets krav om lejlighedsvise fremstod ud fra den fornuftige betragtning, at det ville vare unyttigt spild af menneskeliv. Som typisk for adskil- 
lige dage kan nok gælde folgende melding fra den 30. august kl. (i) morgen:

„1 Nat har alt været roligt. Natpatrouillerne har meldt: 1. At de staaende Patrouiller fra Brechendorff-Veien er udsat paa sædvanlig Sted, uden at stade paa Fjenden; om Byen er besat vides endnu ikke; et fjendt. Comd: af begge Vaaben, har som Sporene udvise i Nat staaet tat Nord for Byen. - 2. C.-posten ved Kropperbusch udsat uden at Fjenden har søgt at forhindre dette. Fjendens Poster som sædvanligen ved Heidbunge". Meldingen ${ }^{11}$ er skrevet af forpostkommandøren Cai Hegermann-Lindencrone og stilet til 2. infanteri-brigade, Bustrup.

Hvordan situationen tog sig ud set med en menigs øjne fremgår af et brev fra gardisten Jens Peter Lyngbye skrevet den 27. august til søsteren Dorthea hjemme $i$ den fædrene gård $i$ det sjællandske Lyngby:

Jeg kan lade dig vide, at jeg har modtaget to Skjorter og et Par Hoser fra Eder. I Hoserne laa jo to Rdl. i Sølv, hvorfor jeg takker jer for det sendende, men jeg trængte ei til det. Jeg har solgt den ene Skjorte for $1 \mathrm{Rdl}$, for jeg kunde ei føre den med mig, vi haver jo Bepakning nok endda. I maa ei sende mig flere Penge for hen under November, for ellers stjæler de dem fra mig, altsaa ere de ingen Nytte til. Men med Pakken modtog jeg ei noget Brev. Hvorfor kunde I ikke sende mig Brev med Pakken, det var jo besynderligt nok. Jeg haver sendt nu tre Breve til Eder, siden jeg modtog noget Brev fra dig, kære Tea. Jeg onsker snart at komme hjem til Eder, men der er ingen Udsigter til det, maaske ikke før henunder Jul engang. Nu er vi rigtignok kommen $i$ Hus, men vi ligger jo i Halm altid. Somme Nætter maa vi jo ogsaa ligge paa Marken. I kan tro, det er haardt. Regnevejr er det jo altid, hvorved vi faar meget Kulde, men kære Søster, sig til Fader og Moder, at de maa ei være bedrovet over mig, for jeg finder mig godt i den Skæbne. Lad mig nu bare se, at I morer og fornøjer jer, for hernede er vi kede af at ligge. Nætterne begynder at blive kolde og lange, men med Guds Hjælp forventer jeg dog at komme hjem til Eder, saa vil det jo ogsaa blive en Glæde for mig og for Eder allesammen. Er der noget nyt derhjemme, så må I ej lade det gaa forbi mig, uden I lader mig det vide. Jeg opfører mig herovre, saa I skal nok have Glæde af mig. I skal ei 
være bedrøvet, fordi jeg er saa langt fra Hjemmet. Hjemmet er dog det kæreste. Vi maa nu gaa og arbejde paa Danevirke. Der var nogle russiske Generaler og besaa de Forskansninger. Der var en Stab paa omtrent halvtredsindstyve Ordonanser, det var smukt at se, kan I tro. For resten er her intet nyt. Jeg er ved god Helsen, Gud ske Lov og Tak, og det samme onsker jeg at høre fra Eder alle sammen. Gud hjælpe, Gud styrke vore. Nu onsker jeg Eder al Held og Lykke.... fra din oprigtige Broder, Jens Eriksen Lyngbye i den kongelige Livgarde til Fods, 4. Compagni, i Armeen, Slesvig.

I familiens eje gemtes dette brev som et interessant minde $\mathrm{i}$ årene fremover. Halvfems år efter, da de tyske hære atter gik over vor grænse, fik det ligesom fornyet interesse, og man mente da, livad den brave Jens nxppe har drømt om, at landsoldatens brev måtte kunne interessere landets konge. Kong Christian $X$ fik brevet tilsendt og læste det med den interesse, han stedse lagde for dagen for vore historiske minder. Han påskonnede ligeledes den smukke tanke, at man ville forære ham det fortrostningsfulde brev i en alvorlig stund; men han fandt dog, at det var bedre, om brevet kom til en offentlig samling og foreslog derfor, at brevet skænkedes til Koldinghus, hvad også senere skete.

Med krigen og sejrene fulgte heltedyrkelsen, som gav sig markanle udslag i kunsten, både digtningen og billedkunsten. Magtfuldt og myndigt har Grundtvig i sit storslåede drapa og Bissen i sin stolte løve tolket sejrens patos og dens dyre pris. Med herosdyrkelsen fulgte atter respekten for relikvien, det personlige minde, tingen med affektionsværdi.

Blandt Isted-dagens store tab føltes vel oberst Læssøes fald særlig hårdt på grund af den respekt, der stod om hans evner og karakter, og fordi man stillede så store forventninger til ham. Tidligere på året havde han til broderen Joseph Læssøe $i$ et brev, ${ }^{12}$ der ellers mest handler om forretningssager citeret „dristigt vovet, er halvt vundet", et citat med personlig dækning. Efter hans fald har pietetsfulde hænder $\mathrm{i}$ mere end hundrede år taget vare på en lok af hans hår, hans skærf, epauletter, distinktioner, feltsalmebog og blyant med guld-navneplade samt danebrogsordenens solvkors, som han havde fået året før, mens ridderkorset fra 1848, 


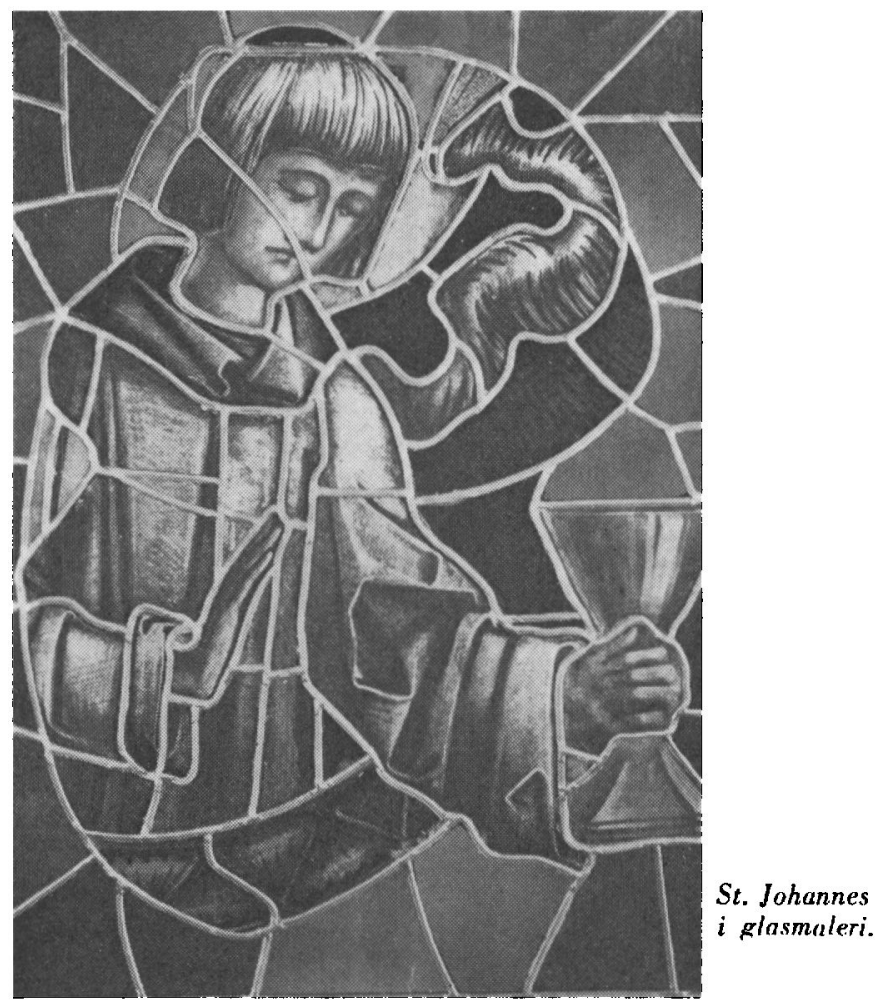

som statulterne kræver det, er blevet tillageleveret. Nylig er disse mindestykker kommet til Koldinghus .

Efter Isted-slaget troede man, at nu var "ledet i lave". Men mindre end fjorten år efter gik den danske hær den tunge snefogs vandring fra Danevirke til Dybbøl. Derefter var Isted tysk. Til slagets ihukommelse blev der rejst en "Gedächtniskirche“ med glasmalerier i de pseudogotiske vinduer. I forvirringens år efter 2. verdenskrig kom disse vinduer $i$ handelen i små stykker. En del af glasset blev lavet til lygter. Et lidt større sammenlængende stykke er havnet på Koldinghus, hvor nu apostlen Johannes med kalken i hånden har fået den uvante opgave at vidne om det store slag den 25. juli 1850 . 


\section{NOTER}

1. Oldsayssamlingen i Kolding 1877-1952; Arb Vejle 1952, 141-49.

2. Malerier på Koldinghus, 1960, 36. Jürgen Ovens, Ausstellung im Städtischen Museum Flenslourg 1963, 21.

3. Ms. 1869 Koldinghus.

4. Ms. 3123 Koldinghus. J. Bülow skriver to gange Store Solt, som dog lå et stykke bag de danske linier, formentlig er det skrivefejl for det i slagets topografi mere velkendte Øvre Stolk.

5. whan har Lykke", J. Th. Rader: Krigserindringer, 1911, 251.

6. Ms. 2708 Koldinghus.

7. General de Mezas Krigs-l)agboger, 1928, 124.

8. J. 'Th. Rader: Krigserindringer, $1911,251$.

9. Rockstroh $i$ sin biografi af generalen, de M(»as Krigs-J)agbogger, $1928, \mathrm{XXXV}$.

10. Inv. 1437, skxnket af grevinde Sophic Magdalene Mollke, general Kroghs datterdatter.

11. Ms. 8987 Koldinghus.

12. Ms. 1570 Koldinghus.

13. »Fra 48 , udstillingskatalog 1893 , navner som nr. 1193 feltsalmebogen og nr. 1195 en lok af Laessies hír, begge tilhorende malerinden frøken Augusta Lrssue. 